\title{
SABERES E PRÁTICAS DOCENTES NO PROCESSO DE ENSINO-APRENDIZAGEM EM ADMINISTRAÇÃO: UMA REVISÃO DE ESCOPO
}

\author{
PEDAGOGICAL KNOWLEDGE AND PRACTICES IN THE \\ BUSINESS MANAGEMENT TEACHING-LEARNING PROCESS: \\ A SCOPING REVIEW
}

\section{CONOCIMIENTOS Y PRÁCTICAS DE LOS DOCENTES EN EL PROCESO DE ENSEÑANZA-APRENDIZAJE EN ADMINISTRACIÓN: UNA REVISIÓN DEL ALCANCE}

\author{
Marcelo Oliveira Junior ${ }^{1}$ \\ https://orcid.org/0000-0001-9683-4306 \\ Cléria Donizete da Silva Lourenço ${ }^{2}$ \\ https://orcid.org/0000-0002-5446-7648 \\ Rafael Rodolfo Sartorelli Sadocco ${ }^{3}$ \\ https://orcid.org/0000-0002-2051-379X \\ Iasmin Ribeiro Diniz ${ }^{4}$ \\ https://orcid.org/0000-0002-5762-7491
}

1 Universidade Federal de Lavras, Lavras, Minas Gerais - Brasil. E-mail: marcelo.junior5@estudante.ufla.br.

${ }^{2}$ Universidade Federal de Lavras, Lavras, Minas Gerais - Brasil. E-mail: cleria@ufla.br.

${ }^{3}$ Escola Superior de Propaganda e Marketing, São Paulo - Brasil. E-mail: rafael.sadocco@gmail.com.

${ }^{4}$ Universidade Federal de Lavras, Lavras, Minas Gerais - Brasil. E-mail: iasminrd@ hotmail.com.

\section{Resumo}

Neste artigo buscou-se verificar como a literatura científica tem tratado os saberes que são articulados nas práticas docentes, em um contexto de ensino-aprendizagem em Administração. Tendo em vista tal objetivo, recorreu-se à revisão de escopo de seis artigos científicos, publicados em língua inglesa entre os anos de 1997 e 2018 em periódicos internacionais. Como resultado principal, identificaram-se sete saberes relacionados à avaliação, ao ensino, à estruturação curricular e definição de conteúdo, à política, à interpretação de papéis, ao contexto cultural e à simulação organizacional como estratégia de ensino. Esses saberes, mesmo aqueles suportados pelos conhecimentos didático-pedagógicos, são atravessados pelos saberes que os professores de administração constroem durante sua trajetória de vida, influenciando a forma 
como são articulados. $\mathrm{O}$ artigo contribui teoricamente ao evidenciar que esses saberes, ao serem articulados nas práticas dos professores de administração, são influenciados por seus interesses, o que configura brechas para estudos empíricos que considerem essas categorias de análise.

Palavras-chave: Revisão de escopo. Saberes docentes. Práticas de professores. Formação de professores.

\begin{abstract}
This article sought to verify how the literature has treated knowledge articulated in teaching practices in the context of teaching and learning in Management. To this end, this study consists of a scoping review of six scientific articles published in English between 1997 and 2018 in international journals. The results indicate seven knowledge articulated to teaching practices, namely evaluation, teaching, curriculum structuring and content definition, politics, role interpretation, cultural context, and organizational simulation. These pieces of knowledge, even those supported by didactic-pedagogical knowledge, are crossed by those built during the life trajectory of Management professors, thus influencing the way they are articulated. This study presents an important theoretical contribution to the literature, showing that these pieces of knowledge are influenced by professors' interests when articulated to their pedagogical practices, creating potential gaps for empirical studies that consider these analytical categories.
\end{abstract}

Keywords: Scoping review. Teaching knowledge. Pedagogical practices. Teacher's training.

\title{
Resumen
}

Este artículo busca verificar cómo la literatura científica ha tratado el conocimiento que se articula en las prácticas de profesores, en un contexto de enseñanza y aprendizaje de Administración. En vista de este objetivo, se utilizó una revisión del alcance de seis artículos científicos publicados en inglés, entre 1997 y 2018, en revistas internacionales. Como resultado principal, se identificaron siete conocimientos relacionados con evaluación, enseñanza, estructuración curricular y definición de contenido, política, interpretación de roles, contexto cultural y simulación organizacional como estrategia de enseñanza. Estos conocimientos, incluso los que están respaldados por el conocimiento didáctico-pedagógico, se cruzan con el conocimiento que los profesores de Administración construyen durante su trayectoria de vida, influyendo en la forma en que se articulan. El artículo contribuye teóricamente, al mostrar que estos conocimientos, cuando se articulan en las prácticas de los profesores de Administración, están influenciados por sus intereses, lo que configura brechas para los estudios empíricos que consideran estas categorías de análisis.

Palabras clave: Revisión del alcance. Conocimiento de profesores. Prácticas docentes. Formación de professores.

\section{Introdução}

Não é recente o apelo para que os cursos de pós-graduação em Administração no Brasil, responsáveis pela formação de professores do ensino superior, promovam práticas formais de melhoria do processo de ensino-aprendizagem (FISCHER, 2006). A incorporação da lógica 
neoliberal às políticas universitárias coloca o foco das ações capitaneadas pelas instituições de ensino superior, sobretudo as públicas, na pesquisa e na inovação (SILVA JÚNIOR; SCHUGURENSKY; ARAÚJO, 2015). Como se observa no Plano Nacional da Pós-Graduação, vigente de 2011 a 2020, a preocupação com a pesquisa, que privilegia a articulação entre universidades, empresas e governo, é um dos principais fundamentos norteadores das políticas educacionais para a pós-graduação (BRASIL, 2010).

O que nos parece paradoxal, no entanto, é que os indicadores de qualidade do ensino são suportes para que sejam formuladas e reformuladas políticas de melhoria educacional. No entanto, o ensino parece não ser devidamente contemplado nessas mesmas políticas. A qualidade do ensino depende das habilidades, dos conhecimentos e atitudes dos professores, tal que sejam capazes de mobilizar seus saberes em virtude das necessidades de aprendizagem dos estudantes. Os professores que têm sucesso no ensino são aqueles que proporcionam a melhor aprendizagem para os estudantes, ao conciliar o conhecimento do conteúdo de sua área de especialização com conhecimentos didático-pedagógicos (WALSHAW, 2012).

Ademais, as competências dos professores - que compreendem seus conhecimentos, habilidades e atitudes - são atravessadas por suas experiências, de modo que influenciam a forma como realizam suas práticas na docência (CISHE; MANTLANA; NYEMBEZI, 2015), que de maneira mais ampla se traduzem naquilo "que muitas vezes foi chamado de saber, saberfazer e saber-ser" (TARDIF, 2000, p. 11). Uma lente teórica que pode auxiliar a compreensão das articulações entre saberes e práticas dos professores é a abordagem da prática social (MARDAHL-HANSEN, 2019).

Ao se considerar que as práticas docentes não possuem um repertório cristalizado de elementos a serem seguidos, mas, por ser um trabalho em que o sujeito (o professor) lida com um objeto não inerte (o estudante) que muitas vezes pode lhe oferecer resistência em suas práticas (o ensino) (TARDIF; LESSARD, 2009), entendemos a necessidade de investigação nesse sentido, tal que nos questionamos: “que saberes os professores articulam nas práticas docentes no contexto de ensino-aprendizagem em Administração?” Diante de tal questionamento, o objetivo do presente estudo foi verificar como a literatura científica tem tratado os saberes que são articulados nas práticas docentes, em um contexto de ensinoaprendizagem em Administração.

O presente trabalho, além desta introdução, traz aspectos teóricos para elucidar o leitor sobre a proposta do estudo, evidencia os procedimentos metodológicos que foram realizados, 
aponta os resultados encontrados e discute-os à luz da literatura pertinente, e realiza algumas considerações finais sobre as principais constatações.

\section{Aspectos ontoepistemológicos das teorias da prática}

Originalmente, a epistemologia tinha por objetivo estabelecer os limites do que seria ou não ciência, abarcando, sobretudo, o pensamento funcional-positivista como o mais adequado para a reflexão sobre a realidade. Somente em meados da década de 1960 houve uma flexibilização epistemológica, que permitiu que outros "objetos epistêmicos", sobretudo os oriundos da realidade social (como a linguagem, por exemplo), pudessem ser examinados empiricamente (TARDIF, 2000). Com isso, a teoria social passou a receber uma pluralidade teórico-metodológica (SANTOS; ALCADIPANI, 2015) que implicou no crescimento dos dualismos nas ciências sociais, tais como o macro/micro, objetivo/subjetivo e determinismo/voluntarismo, para citar alguns.

Ao observar esses antagonismos teóricos, alguns autores passaram a defender a ideia de que há, na verdade, uma dualidade (em substituição ao dualismo) em que aspectos objetivos e subjetivos, por exemplo, se entrelaçam na realidade social, de modo que um não nega a existência do outro, mas ambos coexistem e produzem mutuamente a realidade social. Nascem, então, os estudos baseados na prática, terminologia que, inicialmente, foi designada para destacar os trabalhos de Pierre Bourdieu, Anthony Giddens e Michel Foucault (RECKWITZ, 2002), acrescendo, posteriormente, autores como Andreas Reckwitz, Elizabeth Shove e Stephen Kemmis (SCHATZKI, 2012).

Anthony Giddens, com sua teoria da estruturação, objetiva superar as dicotomias da análise sociológica tradicional; por isso, não se ancora epistemologicamente, visto que, ao fazêlo, entraria em contradição consigo mesmo. Assim, ontologicamente, Giddens nos ensina que a estrutura social é mantida por eventos em que as ações (agência) individuais se encontram, de modo que estrutura e agência se constituem intersubjetivamente ao imprimir características de si no outro. Aqui, são as práticas que conectam os agentes à estrutura, e devem, assim, ser o foco das análises sociais (COHEN, 1999; ROSSONI; GUARIDO FILHO; CORAIOLA, 2013).

Conforme nos ensinou Bourdieu (2011), devemos ter cuidado para apreender as práticas, porque, segundo o autor francês, elas estão completamente associadas ao contexto (posição sócio-histórica) em que são praticadas. Os atores se posicionam socialmente em virtude de seu acesso aos capitais econômico e cultural, e as suas práticas correspondem aos 
estilos dessas posições. Isso significa, por exemplo, que um praticante de um esporte tido como nobre pode não mais o praticar caso um ator de uma posição social diferente (mais baixa) comece a fazê-lo. Analogamente, Schatzki (2017) sugere que, ontologicamente, tanto o lugar (entenda-se "contexto") em que as práticas ocorrem como elas próprias acabam por se constituir mutuamente em um campo inteligível (permeado de significados) aos praticantes.

A pluralidade de perspectivas teóricas por trás dos estudos baseados nas práticas, conforme demonstrou Gherardi (2016), implica em diferenças que se situam, em resumo, na centralidade que determinadas teorias dão aos humanos, por um lado, e à concessão de status igual aos elementos não humanos, ${ }^{1}$ por outro. A autora não defende, no entanto, a unificação das teorias da prática; pelo contrário, são as diferenças teóricas que trazem sentido para o estudo das práticas, visto que elas são essencialmente diferentes e diferenciadoras, porque são praticadas de maneiras diferentes pelos atores.

Uma proposta de epistemologia da prática (RECKWITZ, 2002), portanto, não busca trazer um significado único às práticas, mas sim "uma definição de pesquisa, isto é, uma proposta com o fim de construir e delimitar um objeto de pesquisa, um compromisso em favor de certas posturas teóricas e metodológicas" (TARDIF, 2000, p. 13). Assim, Tardif (2000, p. 13) chama de epistemologia da prática profissional "o estudo do conjunto de saberes utilizados realmente pelos profissionais em seu espaço de trabalho cotidiano para desempenhar todas as suas tarefas".

\section{Docência como prática}

Uma prática não necessariamente se refere às atividades objetivas dos indivíduos (embora também o seja), mas, sobretudo, às suas experiências que vão se acumulando no decorrer da história. Nesse sentido, as práticas ocorrem no cotidiano das pessoas, ao conciliarem recursos materiais com seus entendimentos sobre o funcionamento daquela prática (CISHE; MANTLANA; NYEMBEZI, 2015).

Schatzki (2017) sugere que a prática social é um conjunto (nexo) de práticas (além do agrupamento e organização dos indivíduos) que se diferenciam umas das outras em função das

\footnotetext{
${ }^{1}$ A influência dos elementos não humanos na tessitura social foi introduzida por Bruno Latour (2011). Sob esse entendimento, pôde-se notar que as práticas são articulações em que os agentes usam de determinados objetos da realidade objetiva para as conduzir. Mais especificamente, algumas práticas são mediadas por determinados objetos do mundo físico (como uma lousa que é usada para a prática do ensino, por exemplo).
} 
demandas específicas às suas finalidades. Assim, "a prática de ensino pode ser entendida como um conjunto de atividades, processos, preocupações e tarefas diferentes que devem ser coordenadas entre si na prática da escola com recursos limitados" (MARDAHL-HANSEN, 2019, p. 9).

Do ponto de vista da educação, a prática se relaciona aos comportamentos dos professores dentro e fora da sala de aula, e que são direcionados pelos conhecimentos que consideram válidos (CISHE; MANTLANA; NYEMBEZI, 2015). Isso significa que as práticas docentes estão diretamente ligadas à didática, uma vez que a segunda é responsável pelas "teorizações e fundamentações conceituais e procedimentais sobre a relação entre professores e alunos em torno do conhecimento em situações determinadas de ensinar e aprender. Assim, a didática [...] cria saberes fundamentais para a formação e a prática profissional de professores" (CRUZ, 2017, p. 674). Não significa, no entanto, que estamos condicionando as práticas docentes apenas aos conhecimentos didáticos, porque isso invalidaria a influência da trajetória de vida dos professores em suas práticas. O que estamos dizendo, na verdade, é que os professores mobilizam seus saberes (suas experiências, seus conhecimentos pedagógicos, científicos e empíricos) para realizar suas práticas em seus cotidianos.

É nesse sentido que Perrenoud et al. (2018, p. 13) questionam "que tipo de conhecimentos o professor especialista mobiliza, e como esses conhecimentos se articulam a outros recursos cognitivos". Os autores respondem essa questão sugerindo que os conhecimentos dos professores são de natureza funcional, distinguindo-se em conhecimentos teóricos - relativos aos conhecimentos didático-pedagógicos e científicos (que se referem à disciplina que o professor leciona) - e conhecimentos práticos ou empíricos - que são adquiridos pelos sujeitos através de suas experiências profissionais e trajetória de vida. Vale ressaltar que esses conhecimentos não são prescritivos, de modo que sua observância seja compulsória. $\mathrm{Na}$ verdade, os docentes (metaforicamente) possuem uma caixa de ferramentas que carregam consigo, sem que necessariamente usem todas as ferramentas ali presentes em uma determinada aula. Eles as têm para que as usem em momentos em que talvez sejam necessárias, permitindo, portanto, o improviso e a criatividade em situações não previstas (TARDIF; LESSARD, 2009).

Os elementos que têm sido discutidos ao longo do texto podem subsidiar a compreensão das práticas docentes em Administração, principalmente porque os poucos estudos empíricos nesse sentido têm avaliado, predominantemente, os conhecimentos científicos que os 
professores possuem (KUHN; ALONZO; ZLATKIN-TROITSCHANSKAIA, 2016), sendo tais conhecimentos apenas um dos elementos que devem ser observados. O melhor entendimento sobre as práticas dos docentes de Administração implicaria na formulação de estratégias de ensino que conciliam o protagonismo do estudante no processo de ensinoaprendizagem (BROOK; MILNER, 2014).

\section{Percurso metodológico}

No presente trabalho, optamos pelo uso da revisão de escopo (scoping review), também conhecida como "revisão de mapeamento" ou "estudo de escopo", que é uma análise exploratória que mapeia evidências ainda pouco trabalhadas na literatura. Em muitos casos, as revisões de escopo servem como um suporte para futuras revisões sistemáticas ou integrativas, quando, nesses casos, a literatura sobre o tema já está consolidada. Ressaltamos também que as revisões de escopo permitem a análise de dados quantitativos e qualitativos, a critério do pesquisador, observando sempre a questão que norteia sua análise (PETERS et al., 2017).

Neste estudo nos baseamos nas instruções do Joanna Briggs Institute (JBI) (PETERS, 2017). Inicialmente, estipulamos um protocolo de inclusão e exclusão dos trabalhos que viriam a fazer parte do conjunto de textos a serem estudados. Essa etapa está fortemente ligada à questão que norteia a análise dos textos. Aqui, seguimos a estratégia population, concept e context (população, conceito e contexto - PCC), sendo definido, portanto: $(\mathrm{P})$ professores, $(\mathrm{C})$ práticas docentes e (C) ensino-aprendizagem em Administração. Ademais, consideramos, para composição do conjunto de textos a serem analisados, artigos científicos resultantes de estudos empíricos publicados em anais de eventos ou periódicos indexados nas bases de dados Web of Science (WoS) e Scopus. Optamos por tais plataformas porque permitem concomitantemente o acesso a mais de 28 mil periódicos científicos (DARDAS et al., 2019).

Os termos de busca (Quadro 1) foram inseridos nas ferramentas de busca avançada de ambas as bases. Nessa etapa, somados aos termos de busca, foram utilizados operadores booleanos (“AND" e "OR”), a fim de obtermos o conjunto de textos mais próximo possível daquele que nos interessa. Salientamos que os termos foram buscados nos títulos dos documentos, e que a busca ocorreu em outubro de 2019. 
Quadro 1 - Termos de busca e resultados iniciais.

\begin{tabular}{|c|c|c|c|c|c|c|}
\hline & & Scopus & $\mathbf{n}_{1}$ & WoS & $\mathbf{n}_{2}$ & Total \\
\hline $\begin{array}{c}\text { "business education" } \\
\text { OR }\end{array}$ & AND & practi? $e^{*}$ & 19 & practi? $e^{*}$ & 12 & 31 \\
\hline \multicolumn{7}{|l|}{ OR } \\
\hline \multicolumn{7}{|l|}{ OR } \\
\hline "management teaching" & AND & practi? $e^{*}$ & 6 & practi? $e^{*}$ & 9 & 15 \\
\hline & & & 126 & & 87 & 213 \\
\hline
\end{tabular}

Nota: As colunas " $n_{1}$ " e " $n_{2}$ " dizem respeito ao número de documentos encontrados em cada base de dados.

Fonte: Elaborado pelos autores (2022).

Os dados (autores, título, resumo, palavras-chave, veículo de publicação e tipo de documento) dos 213 documentos foram recuperados das bases de dados e inseridos numa planilha eletrônica para serem tratados. O primeiro passo foi a verificação de repetições de textos numa mesma base de dados (sete na Scopus e um na WoS) e entre as bases (52 textos). Com isso, um conjunto unificado foi estabelecido, formado por 153 documentos (Figura 1), entre capítulos de livros, proceeding papers, resumos, resenhas e livros.

Figura 1 - Conjunto inicial de documentos a serem avaliados.

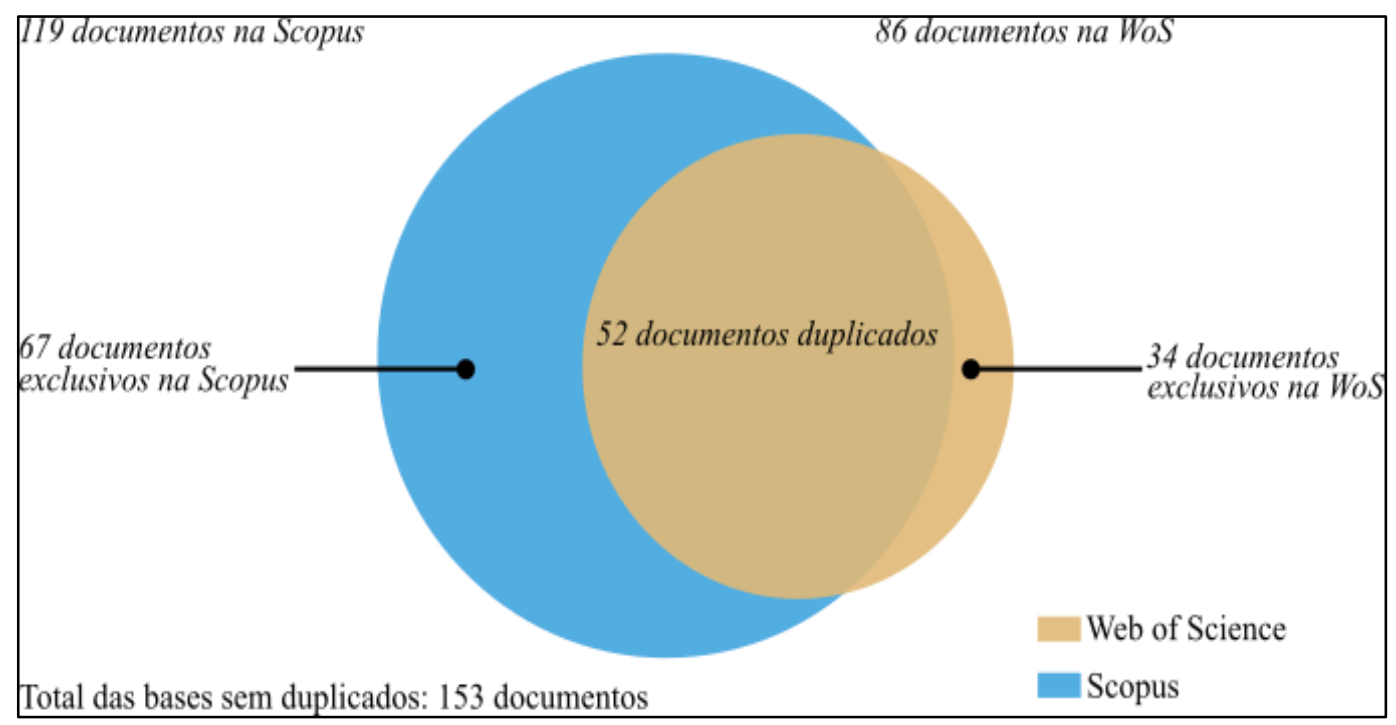

Fonte: Elaborada pelos autores (2022). 
Desse conjunto, excluímos os documentos que não eram artigos científicos publicados em anais de eventos ou periódicos (46). O resultado dessa etapa (107) passa a compor, agora, um único banco de dados (com os artigos de ambas as bases de dados). Esses textos foram submetidos a análises de título, resumo e palavras-chave, buscando evidências que os aproximassem da questão norteadora do estudo. Finalmente, após essa etapa, 11 artigos foram aceitos para a leitura completa. A Figura 2 demonstra os processos de filtragem.

Figura 2 - Esquema do processo de filtragem dos documentos.

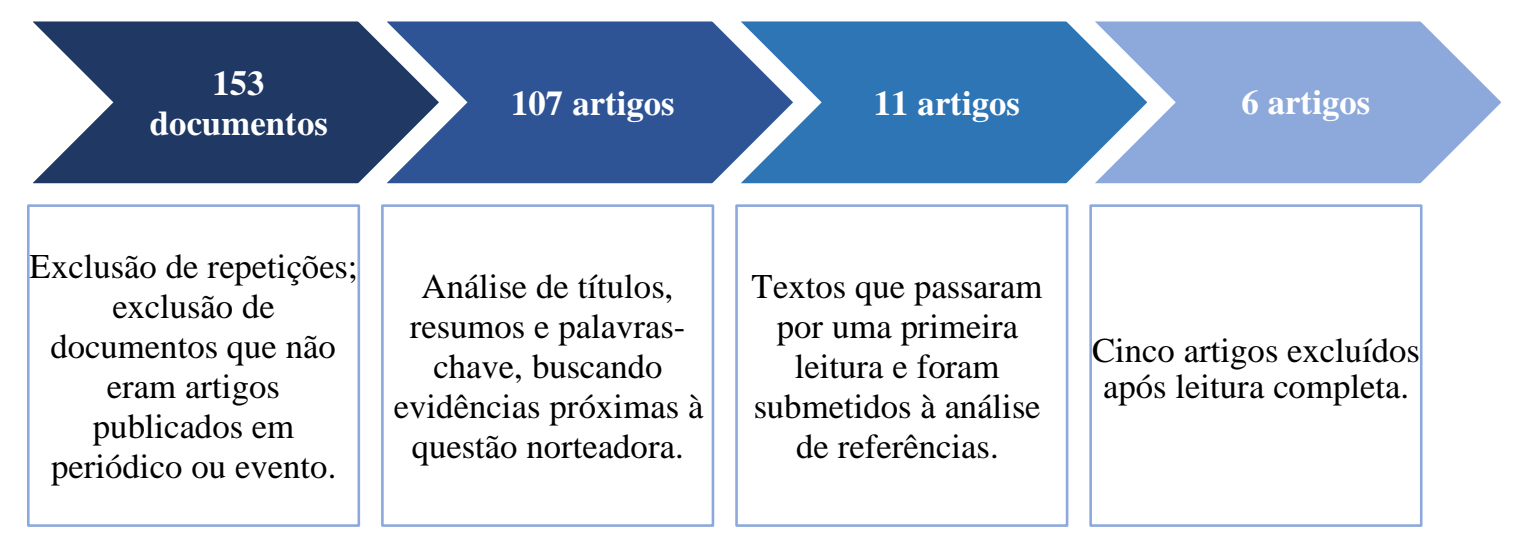

Fonte: Elaborada pelos autores (2022).

Após a leitura integral dos 11 artigos selecionados em primeira instância, esses foram submetidos à análise de referências, mas não houve textos que pudessem ser acrescidos ao conjunto final. Durante a leitura integral dos artigos, alguns textos que anteriormente foram aceitos no processo de leitura dos tópicos foram excluídos, por não serem plenamente adequados à proposta deste estudo. Assim, o conjunto final foi composto por seis artigos.

Finalmente, ao seguirmos as recomendações do JBI (PETERS, 2017), extraímos os seguintes dados (realizando algumas adaptações) dos textos selecionados: autor(es), ano de publicação, veículo de publicação, país de origem onde o estudo foi realizado, objetivos/finalidade, metodologia/métodos, principais descobertas e suas relações com a pergunta da revisão do escopo. 


\section{Resultados}

Nesta seção, apresentamos os resultados da pesquisa: em primeiro lugar, observarmos que alguns artigos foram excluídos do conjunto final após a leitura completa; em seguida, trazemos os dados dos artigos que foram aceitos para as análises; e, finalmente, evidenciamos algumas implicações para a docência em Administração.

\subsection{Textos aceitos na leitura dos tópicos e excluídos na leitura final}

O texto "The use of case studies in pre-experience business education: Part II: Using case studies effectively" de autoria de Jerry Forrester e Margaret Oldham, publicado em 1981, foi excluído por não se tratar de trabalho empírico, mas sim de texto teórico-argumentativo em que os autores defendem o uso do estudo de caso como forma de melhoria da aprendizagem dos estudantes de Administração. O trabalho oferece diretrizes para o uso eficaz de estudos de caso, abrangendo a seleção de material, o papel do professor, formas alternativas de usar estudos de caso e dificuldades que podem ser encontradas por professores e alunos.

Em "The practice of management education in Australian universities", publicado em 2004 por Rosalie Holian, há uma discussão teórica no contexto da educação gerencial australiana, apontando as dificuldades que os gestores podem enfrentar ao assumir a docência e vice-versa, e as lacunas que a educação gerencial apresenta quando comparada com a aprendizagem que ocorre no cotidiano das organizações, por meio de cursos de curto prazo, capacitações e treinamentos. $\mathrm{O}$ artigo nos convida a pensarmos se a educação gerencial formal (universitária) pode ser substituída.

$\mathrm{O}$ artigo "Bridging the divide between theory and practice: experiential learning approaches for tourism and hospitality management education" publicado em 2006 por Lisa Ruhanen, trata de práticas de adoção de papéis como forma de ensino e aprendizagem contudo, a realidade estudada é de um curso de turismo e hotelaria. $\mathrm{O}$ artigo contribui ao sugerir que os professores podem assumir papéis que os levam a readequar sua conduta em virtude das especificidades do contexto e das demandas dos estudantes.

A respeito do contexto de ensino-aprendizagem em contabilidade na China, o artigo publicado em 2015 por Jie Xu e Lei Wang, intitulado “'Financial management' teaching practice research based on EBL teaching model", explora um modo de ensino adaptado da 
aprendizagem baseada em problemas, denominado "aprendizagem baseado em empresas". As autoras apontam que o uso do método integra conhecimentos teóricos que são abstratos, e os contextualiza numa prática empreendedora. Como resultado, os estudantes se sentem mais motivados a buscar o conhecimento teórico, pois o aplicam cotidianamente na prática empresarial.

Finalmente, em "Enhancing reflective practices within business management education: what kinds of e-learning scenarios can be designed?", Terry Inglese, Michael Von Kutzschenbach e Hans-Friedrich Witschel (2019) discutem como a aprendizagem reflexiva pode mudar o comportamento de estudantes de um curso de mestrado em Administração. Para isso, eles relatam a experiência de uma disciplina em que profissionais são convidados a palestrar e os professores instigam os estudantes a preparar perguntas reflexivas para os palestrantes. Como resultado, ao refletirem sobre a trajetória dos convidados e discutirem suas experiências, os estudantes tornam-se mais reflexivos quanto à sua própria formação e perspectivas futuras.

\subsection{Apresentação e discussão dos dados}

Os textos selecionados para análise compreendem um intervalo de pouco mais de 20 anos (1997 a 2018) e se assemelham ao discutir as especificidades do processo de ensinoaprendizagem em Administração. No Quadro 2, a primeira coluna (id) à esquerda enumera os textos de modo que sejam identificados no Quadro 3. Nesse, por exemplo, o objetivo descrito sob o "id 1" refere-se ao "id 1" apresentado naquele. 
Quadro 2 - Ano de publicação, autor(es), título e veículo de publicação do conjunto de artigos analisados.

\begin{tabular}{|c|c|c|c|c|}
\hline id & Ano & Autor(es) & Título & Veículo de publicação \\
\hline 1 & 1997 & Giri, A. K. & $\begin{array}{l}\text { "Management education and the teaching } \\
\text { of ethics: pedagogy, practice and the } \\
\text { challenge of a new initiative" }\end{array}$ & Journal of Human Values \\
\hline 2 & 2003 & $\begin{array}{l}\text { Romme, A. G. L.; } \\
\text { Putzel, R. }\end{array}$ & $\begin{array}{l}\text { "Designing management education: } \\
\text { practice what you teach" }\end{array}$ & Simulation \& Gaming \\
\hline 3 & 2008 & Adetayo, J. & $\begin{array}{l}\text { "An investigation of assessment practices } \\
\text { by teachers business education subjects" }\end{array}$ & $\begin{array}{l}\text { Academic Leadership: The } \\
\text { Online Journal }\end{array}$ \\
\hline 4 & 2011 & $\begin{array}{l}\text { Benson, V.; Anderson, } \\
\text { D.; Ooms, A. }\end{array}$ & $\begin{array}{l}\text { "Educators' perceptions, attitudes and } \\
\text { practices: blended learning in business } \\
\text { and management education", }\end{array}$ & $\begin{array}{l}\text { Research in Learning } \\
\text { Technology }\end{array}$ \\
\hline 5 & 2016 & $\begin{array}{l}\text { Hoidn, S.; Olbert- } \\
\text { Bock, S. }\end{array}$ & $\begin{array}{l}\text { "Learning and teaching research } \\
\text { methods in management education: } \\
\text { development of a curriculum to combine } \\
\text { theory and practice: a Swiss case" }\end{array}$ & $\begin{array}{l}\text { International Journal of } \\
\text { Educational Management }\end{array}$ \\
\hline 6 & 2018 & $\begin{array}{c}\text { Zhang, Y. X. X.; } \\
\text { Fu, P.; Xi, Y. }\end{array}$ & $\begin{array}{l}\text { "Promoting management education in } \\
\text { China through developing practice-based } \\
\text { management theories: an interview with } \\
\text { practitioner-scholar" }\end{array}$ & $\begin{array}{l}\text { Journal of Management } \\
\text { Inquiry }\end{array}$ \\
\hline
\end{tabular}

Fonte: Elaborado pelos autores (2020).

Quanto aos objetivos, observamos que os textos buscam discutir ensino, aprendizagem, avaliação e gestão como variáveis que permeiam o contexto de ensino-aprendizagem em Administração, o que nos permite especular que, aos docentes de Administração, em dados momentos de suas práticas, é necessária a articulação de saberes dessa natureza. 
Quadro 3 - Objetivo, metodologia, técnica de coleta e método de análise.

\begin{tabular}{|c|c|c|c|c|}
\hline id & Objetivo & Metodologia & Procedimento & $\begin{array}{c}\text { Análise } \\
\text { dos dados }\end{array}$ \\
\hline 1 & $\begin{array}{l}\text { Apresentar os temas e problemas do ensino de } \\
\text { ética em escolas de gestão na Índia e nos Estados } \\
\text { Unidos }\end{array}$ & Qualitativa & Estudo de caso & $\begin{array}{c}\text { Não } \\
\text { informado }\end{array}$ \\
\hline 2 & $\begin{array}{l}\text { Explorar como professores de administração } \\
\text { podem apresentar seus conhecimentos não } \\
\text { apenas como conteúdo do curso, mas também } \\
\text { como estrutura da atividade de aprendizado dos } \\
\text { alunos }\end{array}$ & Qualitativa & Estudo de caso & $\begin{array}{c}\text { Não } \\
\text { informado }\end{array}$ \\
\hline 3 & $\begin{array}{l}\text { Descobrir se os professores de administração } \\
\text { avaliam os domínios cognitivo, afetivo e } \\
\text { psicomotor da aprendizagem }\end{array}$ & Quantitativa & Survey & $\begin{array}{l}\text { Estatística } \\
\text { descritiva }\end{array}$ \\
\hline 4 & $\begin{array}{l}\text { Investigar percepções, atitudes e práticas } \\
\text { relacionadas ao aprendizado misto no ensino } \\
\text { superior e identificar fatores que facilitam ou } \\
\text { impedem a adoção e implementação do ensino } \\
\text { misto em uma escola de negócios de uma } \\
\text { universidade de Londres, Reino Unido }\end{array}$ & Qualitativa & $\begin{array}{l}\text { Estudo de caso; } \\
\text { entrevistas } \\
\text { semiestruturadas }\end{array}$ & $\begin{array}{l}\text { Análise de } \\
\text { conteúdo }\end{array}$ \\
\hline 5 & $\begin{array}{l}\text { Apresentar e avaliar um currículo de pesquisa } \\
\text { obrigatória recém-projetado para um programa } \\
\text { de Master of Science in Business Administration, } \\
\text { lançado em } 2008 \text { em uma universidade de } \\
\text { ciências aplicadas na Suíça }\end{array}$ & $\begin{array}{l}\text { Quanti- } \\
\text { qualitativa }\end{array}$ & Estudo de caso & $\begin{array}{c}\text { Não } \\
\text { informado }\end{array}$ \\
\hline 6 & $\begin{array}{l}\text { Discutir a lacuna entre teoria e prática e a } \\
\text { ocidentalização da Administração chinesa } \\
\text { através da perspectiva de Y. M. Xi, estudioso de } \\
\text { administração, líder de escola de negócios, } \\
\text { praticante e agora diretor de universidade }\end{array}$ & Qualitativa & $\begin{array}{l}\text { Entrevista em } \\
\text { profundidade; } \\
\text { história de vida }\end{array}$ & $\begin{array}{c}\text { Não } \\
\text { informado }\end{array}$ \\
\hline
\end{tabular}

Fonte: Elaborado pelos autores (2020).

Outro aspecto interessante se refere aos métodos empregados pelos autores desses textos. Majoritariamente, os trabalhos apresentam resultados de pesquisas qualitativas que têm por procedimento o estudo de caso. Esse fato nos parece sugestivo, uma vez que determinados objetos epistêmicos, sobretudo aqueles carregados de subjetividades, como as práticas docentes, só podem ser apreendidos profundamente por meio de métodos qualitativos de coleta e análise.

\subsection{Saberes empregados na prática docente em Administração}

Nesta subseção, evidenciamos as categorias de saberes que foram observadas nas práticas dos docentes, num contexto de ensino-aprendizagem em Administração. 
- Saberes e práticas na avaliação (ADETAYO, 2008): a avaliação está diretamente ligada à instrução, e, juntas, se conectam à aprendizagem. Isso porque a avaliação não pode se destinar apenas a análises quantitativas que buscam evidenciar o grau de memorização do estudante com relação ao conteúdo. A avaliação, enquanto ferramenta de instrução, considera não somente o desenvolvimento cognitivo, mas o afetivo e o psicomotor. Em outras palavras, considera-se o desenvolvimento de habilidades relacionadas à personalidade do estudante. Uma avaliação deve decorrer dos objetivos instrucionais previamente estabelecidos. É importante que os professores de administração estejam familiarizados com os principais objetivos específicos de sua área de atuação, tal que possam formular objetivos instrucionais que se adequem aos domínios da aprendizagem de tópicos específicos. Com base nos objetivos estabelecidos, o próximo passo é estabelecer um método adequado para se verificar até que ponto esses objetivos estão sendo alcançados. Conforme Adetayo (2008) nos mostra, os professores de administração majoritariamente objetivam verificar apenas a conformidade cognitiva do estudante às "especificações" de um administrador. Assim, as dimensões afetiva e psicomotora são negligenciadas, porque os professores sentem-se mais confortáveis em medir a aprendizagem dos conteúdos específicos que lecionam. Como resultado, os estudantes tendem a se tornar repetidores acríticos do gerencialismo tecnicista que lhes é ensinado, uma vez que sua conduta, fala, postura e sentimentos não são avaliados.

- Saberes e práticas no ensino (BENSON; ANDERSON; OOMS, 2011; GIRI, 1997; ROMME; PUTZEL, 2003): os saberes e práticas relacionados ao ensino são integrados à personalidade do professor e externalizam quem ele é. Indo além, o sucesso no ensino depende da educação, dos valores e da compreensão de mundo do professor (GIRI, 1997). Em especial no ensino de administração, os professores devem buscar ir além do magistério tradicional (ROMME; PUTZEL, 2003), podendo, inclusive, incorporar ferramentas e estratégias de ensino que incluam novas tecnologias de informação e comunicação (BENSON; ANDERSON; OOMS, 2011). O que se observa, no entanto, é que os professores de administração não se sentem confortáveis em lecionar aquilo que foge à sua área de especialização (GIRI, 1997), e, em um outro extremo, podem acabar incorporando ferramentas e estratégias de ensino apenas por suas preferências individuais (BENSON; ANDERSON; OOMS, 2011). 
- Saberes e práticas na estruturação curricular e definição de conteúdos (HOIDN; OLBERTBOCK, 2016; ZHANG; FU; XI, 2018): os professores que se envolvem no processo de estruturação curricular discutem os requisitos do desempenho que se espera dos estudantes, debatem as práticas de classificação de recursos, definem os parâmetros de qualidade da pesquisa e do ensino e trabalham em conjunto com a comunidade acadêmica para refinarem o currículo. Como consequência, esses docentes acabam por desenvolver habilidades administrativas mesmo que não tenham experiência de mercado, uma vez que práticas de gestão são desempenhadas no processo de estruturação curricular. Hoidn e Olbert-Bock (2016) afirmam que os professores devem utilizar esses conhecimentos práticos para envolver os estudantes com exemplos de práticas autênticas de administração, para que se sintam atraídos a participar de uma comunidade de prática. Os docentes devem promover para os alunos experiências produtivas de aprendizagem em que se considerem suas experiências, seus diferentes níveis de conhecimento, restrições de tempo (como no caso de estudantes que trabalham, por exemplo) e interesses, e devem "saber quando e quanto intervir nesses processos cognitivos e sociais", o que demanda "consideração cuidadosa, conhecimento pedagógico e aptidão para o ensino" (HOIDN; OLBERT-BOCK, 2016, p. 52). Ao estruturar o conteúdo a ser aprendido, os professores precisam adequá-lo às bases curriculares, fornecer recursos de aprendizagem, esclarecer os objetivos esperados e desenvolver uma agenda com prazos para os projetos. Finalmente, os professores devem contribuir mutuamente para a construção de um conteúdo integrado e que traga sentido. Isto é, não é recomendado que simplesmente se copiem as teorias e práticas administrativas estrangeiras e as apliquem no contexto regional, pois "as teorias de gestão e o conhecimento precisam ser relevantes para o contexto fornecido" (ZHANG; FU; XI, 2018, p. 217).

- Saberes e práticas políticos (BENSON; ANDERSON; OOMS, 2011; GIRI, 1997; HOIDN; OLBERT-BOCK, 2016; ZHANG; FU; XI, 2018): diretamente ligados aos demais saberes e práticas aqui apresentados, mas muito mais evidentes nos saberes e práticas de estruturação curricular e definição de conteúdos, os saberes e práticas políticos dizem respeito à necessidade de os docentes realizarem negociações para que determinadas ações sejam executadas. A tomada de decisões em um contexto de ensino-aprendizagem em administração implica repercussões diversas para os mais diversos atores envolvidos. Por exemplo, professores que não se sentem confortáveis em contar com o auxílio das tecnologias em suas práticas de ensino podem negligenciar o uso de determinadas ferramentas (BENSON; ANDERSON; OOMS, 2011), contrariando as diretrizes pré- 
estabelecidas. Em outras palavras, nesse campo há conflitos de interesse que podem levar a rupturas nas relações entre pares. As relações entre os professores e os estudantes também podem ser afetadas, uma vez que as ações dos professores são sempre políticas.

- Saberes e práticas na interpretação de papéis (GIRI, 1997; HOIDN; OLBERT-BOCK, 2016; ROMME; PUTZEL, 2003; ZHANG; FU; XI, 2018): os saberes e práticas na interpretação de papéis estão associados aos demais saberes e práticas apresentados. Tratase das mudanças comportamentais que os professores precisam realizar para executar determinadas ações demandadas pelo campo. Em uma aula, por exemplo, o professor pode assumir o papel de gestor, organizando a sala em termos físicos, sugerindo a criação de grupos de discentes, atribuindo responsabilidades aos estudantes e os instruindo quanto às suas ações. Em alguns casos, o professor "se afasta" e observa, a fim de avaliar como o aprendizado tem ocorrido. Não significa que ele se torna passivo no processo. Pelo contrário, sua atividade está em permitir que os estudantes construam o conhecimento conjuntamente. Seu papel assemelha-se ao de um técnico de futebol, que, não estando em campo, mas nas laterais, tem uma visão mais ampla dos acontecimentos do jogo, o que lhe permite articular melhor o time, tomar melhores decisões e buscar que todos trabalhem em virtude de um objetivo comum, que, no caso do futebol, seria a vitória do jogo, mas no caso do processo de ensino-aprendizagem em administração seria a aprendizagem do estudante.

- Saberes e práticas regionais (culturais) (ZHANG; FU; XI, 2018): embora a ciência como um todo tenha se tornado cada vez mais internacionalizada, por meio dos processos de globalização, suportados, em especial, pelas tecnologias da informação e comunicação, a educação administrativa ainda se preocupa com aspectos regionais concernentes à localidade em que o processo educativo ocorre. A compreensão das características culturais de cada localidade - tanto na esfera gerencial pós-curso como no modelo educacional impacta a formatação do processo de ensino-aprendizagem em administração. Na China, por exemplo, os professores se debruçam quase que exclusivamente em livros para conduzir as aulas, enquanto no modelo ocidental os livros servem como suporte em um processo complementado por materiais adicionais, como estudos de caso. Assim, ao professor caberia realizar uma leitura contextual, a fim de buscar inserir no contexto profissional um egresso que tenha as competências demandadas pela realidade por ele vivenciada.

- Saberes e práticas organizacionais na educação administrativa (ROMME; PUTZEL, 2003): o entendimento de como ocorrem as interações em uma organização e o funcionamento de 
seus processos pode ser fomentado no contexto do ensino de administração, em que as práticas administrativas devem ser não apenas transmitidas, mas também vivenciadas. Assim, o professor pode buscar condensar as melhores práticas administrativas e levá-las para o campo de ensino, no qual, alinhadas com as práticas educacionais, devem compor, preferencialmente, um modelo em que os alunos possam se ver retratados em posições correlatas ao mundo organizacional, recebendo funções, sendo avaliados pelos pares, emulando tensões e conflitos que podem ocorrer em um mundo real, mas que se manifestariam igualmente em um ambiente educacional controlado, que requer do educador a construção pertinente dessa simulação. Semelhantemente aos papéis que o professor assume durante sua trajetória profissional, os estudantes também podem assumir papéis que coincidam, em termos de práticas, com os que, porventura, se depararão num contexto organizacional.

\subsection{Implicações à docência em Administração}

Conforme temos discutido, sobretudo pelo que foi evidenciado na subseção anterior, os saberes articulados na prática docente num contexto de ensino-aprendizagem em administração possuem algumas especificidades que, aparentemente, implicam em dificuldades de atuação, como a não formação didático-pedagógica para o professorado. Como consequência, a educação administrativa, mesmo aquela que forma professores (programas de pós-graduação ver, por exemplo, HOIDN; OLBERT-BOCK, 2016), se restringe à replicação de práticas que têm como origem professores que também não tiveram formação didático-pedagógica.

Em virtude desse ciclo, os processos de avaliação, por exemplo, podem acabar não contemplando o desenvolvimento psicomotor e afetivo dos estudantes. Por um lado, é possível que a avaliação de certas habilidades que o estudante pode desenvolver, como a fala e a postura corporal, sejam negligenciadas. Além disso, caso não se preze pela avaliação do desenvolvimento de aspectos afetivos do estudante, pode-se incentivar a formação de um profissional de caráter meramente gerencialista, que desconsidera a importância das relações humanas nas organizações.

A incorporação de novas ferramentas e estratégias de ensino pode auxiliar os professores a fomentar um ambiente de aprendizagem que proporcione aos estudantes autonomia para que possam se desenvolver pessoal, acadêmica e profissionalmente. No 
entanto, embora os professores possam aprimorar seu ensino ao acrescentar ferramentas tecnológicas, as tecnologias da informação e comunicação não podem substituir o professor. Um ambiente de aprendizagem presencial ainda é o mais importante meio pelo qual o processo de ensino-aprendizagem pode ocorrer (BENSON; ANDERSON; OOMS, 2011).

\section{Considerações finais}

Neste artigo, buscamos verificar como a literatura científica tem tratado os saberes que são articulados nas práticas docentes em um contexto de ensino-aprendizagem em Administração. Para tal fim, recorremos à revisão de escopo de um conjunto formado por seis artigos científicos, coincidentemente todos escritos em língua inglesa, publicados entre 1997 e 2018 em periódicos internacionais.

Foram identificados sete saberes relacionados à avaliação, ao ensino, à estruturação curricular e definição de conteúdo, à política, à interpretação de papéis, ao contexto cultural e à simulação organizacional como estratégia de ensino. Esses saberes, mesmo aqueles que são suportados pelos conhecimentos didático-pedagógicos, são atravessados pelos saberes que os professores de administração constroem durante sua trajetória de vida, influenciando a forma como são articulados.

O artigo contribui ao descrever com base em dados empíricos alguns dos saberes a que os professores de administração recorrem para realizar determinadas práticas concernentes à sua profissão. O artigo contribui também ao inovar em seus resultados, uma vez que, na pesquisa científica, quando alguns dos pressupostos ou hipóteses estabelecidos a priori não se confirmam, os pesquisadores tendem a ocultar tais resultados, não observando que as divergências também podem trazer implicações importantes. Assim, neste trabalho, ao assumirmos que alguns textos previamente excluídos também trazem contribuições às nossas descobertas, evidenciamos que nem sempre o resultado esperado é alcançado, mas quando isso ocorre, um novo resultado tão importante quanto emerge.

O estudo se limita pelo número de artigos estudados, o que, por outro lado, pode ser considerado uma potencialidade para estudos futuros. Assim, sugerimos que estudos empíricos sejam conduzidos a fim de se analisar se no contexto nacional esses saberes, que são articulados nas práticas dos professores de administração, se confirmam. Estudos etnográficos e fenomenográficos poderiam ser utilizados para tal fim. 


\section{Referências}

ADETAYO, J. An Investigation of Assessment Practices by Teachers Business Education Subjects. Academic Leadership: The Online Journal, v. 6, n. 3, p. 6, 2008.

BENSON, V.; ANDERSON, D.; OOMS, A. Educator's perceptions, attitudes and practices: blended learning in business and management education. Research in Learning Technology, v. 19, n. 2, p. 143-154, 2011.

BOURDIEU, P. Razões práticas: sobre a teoria da ação. 11. ed. Campinas: Papirus, 2011.

BRASIL. Plano Nacional de Pós-Graduação: PNPG 2011-2020. Brasília, DF: Capes, 2010.

BROOK, C.; MILNER, C. Reflections on "creative" action learning in business education: some issues in its theory and practice. Teaching in Higher Education, Oxfordshire, v. 19, n. 2, p. 126-137, 2014.

CHRISTIE, M. et al. Putting transformative learning into practice. Australian Journal of Adult Learning, Underdale, v. 55, n. 1, p. 9-30, 2015.

CISHE, N.; MANTLANA, D.; NYEMBEZI, N. Teaching practices from a theorical perspective. International Journal of Education Sciences, Haryana, v. 9, n. 2, p. 163-171, 2015 .

COHEN, I. J. Teoria da estruturação e práxis social. In: GIDDENS, A.; TURNER, J. (org.). Teoria social hoje. São Paulo: Editora Unesp, 1999. p. 393-446.

CRUZ, G. B. Didática e docência no ensino superior. Revista Brasileira de Estudos Pedagógicos, Brasília, DF, v. 98, n. 250, p. 672-689, 2017.

DARDAS, L. A. et al. Nursing research in the Arab region: a bibliometric analysis. International Journal of Nursing Practice, Carlton, v. 25, n. 3, art. e12716, 2019.

FISCHER, T. Uma luz sobre as práticas docentes na pós-graduação: a pesquisa sobre ensino e aprendizagem em Administração. Revista de Administração Contemporânea, Rio de Janeiro, v. 10, n. 4, p. 193-197, 2006.

FORRESTER, J.; OLDHAM, M. The use of case studies in pre-experience business education Part II-Using case studies effectively. The Vocational Aspect of Education, v. 33, n. 86, p. 67-71, 1981.

GHERARDI, S. To start practice theorizing anew: the contribution of the concepts of agencement and formativeness. Organization, Thousand Oaks, v. 23, n. 5, p. 680-698, 2016.

GIRI, A. K. Management Education and the Teaching of Ethics: Pedagogy, Practice and the Challenge of a New Initiative. Journal of Human Values, v. 3, n. 1, p. 3-19, 1997.

HOIDN, S.; OLBERT-BOCK, S. Learning and teaching research methods in management education: Development of a curriculum to combine theory and practice-a Swiss case.

International Journal of Educational Management, 2016. 
HOLIAN, R. The practice of management education in Australian universities. Management Decision, 2004.

INGLESE, Terry; VON KUTZSCHENBACH, Michael; WITSCHEL, Hans-Friedrich. Enhancing reflective practices within business management education: what kinds of elearning scenarios can be designed? In: Proceedings of the 10th International Conference on E-Education, E-Business, E-Management and E-Learning. 2019. p. 108-113.

KUHN, C.; ALONZO, A. C.; ZLATKIN-TROITSCHANSKAIA, O. Evaluating the pedagogical content knowledge of pre- and in-service teachers of business and economics to ensure quality of classroom practice in vocational education and training. Empirical Research in Vocational Education and Training, Heidelberg, v. 8, n. 5, art. 5, 2016.

LATOUR, Bruno. Network theory| networks, societies, spheres: Reflections of an actornetwork theorist. International journal of communication, v. 5, p. 15, 2011.

MARDAHL-HANSEN, T. Teaching as a social practice. Nordic Psychology, v. 71, n. 1, p. 3-16, 2019.

PERRENOUD, P. et al. Formando professores profissionais: três conjuntos de questões. In: PERRENOUD, P. et al. (org.). Formando professores profissionais: quais estratégias? Quais competências? 2. ed. Porto Alegre: ArtMed, 2018.

PETERS M. D. J. et al. Scoping reviews. In: AROMATARIS E.; MUNN, Z. The Joanna Briggs Institute Reviewer's Manual. Adelaide: Joanna Briggs Institute, 2017. Chapter 11.

RECKWITZ, A. Toward a theory of social practices: a development in culturalist theorizing. European Journal of Social Theory, London, v. 5, n. 2, p. 243-263, 2002.

ROMME, A. G. L.; PUTZEL, R. Designing management education: Practice what you teach. Simulation \& Gaming, v. 34, n. 4, p. 512-530, 2003.

ROSSONI, L.; GUARIDO FILHO, E. R.; CORAIOLA, D. M. Recomendações metodológicas para a adoção da perspectiva da estruturação nos estudos organizacionais. Organizações e Sociedade, Salvador, v. 20, n. 66, p. 523-542, 2013.

RUHANEN, L. Bridging the divide between theory and practice: Experiential learning approaches for tourism and hospitality management education. Journal of Teaching in Travel \& Tourism, v. 5, n. 4, p. 33-51, 2006.

SANTOS, L. L. S.; ALCADIPANI, R. S. Por uma epistemologia das práticas organizacionais: a contribuição de Theodore Schatzki. Organizações e Sociedade, Salvador, v. 22, n. 72, p. 79-98, 2015.

SCHATZKI, T. R. A primer on practices. In: HIGGS, J. et al. Practice-based education. Rotterdam: Sense Publishers, 2012. p. 13-26.

SCHATZKI, T. R. Persons and practices. Journal of Management Theory and Practice, Kuala Nerus, v. 7, n. 1, p. 26-53, 2017. 
SILVA JÚNIOR, J. R.; SCHUGURENSKY, D.; ARAÚJO, J. B. Ciencia académica, intelectuales y el trabajo del profesor universitario en Brasil: convergencia y hegemonía. Revista de la Educación Superior, Ciudad de México, v. 44, n. 173, p. 157-179, 2015.

TARDIF, M. Saberes profissionais dos professores e conhecimentos universitários. Revista Brasileira de Educação, Rio de Janeiro, n. 13, p. 5-24, 2000.

TARDIF, M.; LESSARD, C. O trabalho docente: elementos para uma teoria da docência como profissão de interações humanas. 5. ed. Petrópolis: Vozes, 2009.

WALSHAW, M. Teacher knowledge as fundamental to effective teaching practice. Journal of Mathematics Teacher Education, Cham, v. 15, n. 3, p. 181-185, 2012.

XU, J.; WANG, L. " Financial Management" Teaching Practice Research Based on EBL Teaching Model. In: 2015 International Conference on Social Science, Education Management and Sports Education. Atlantis Press, 2015. p. 40-43.

ZHANG, X.; FU, P.; XI, Y. Promoting management education in China through developing practice-based management theories: An interview with practitioner-scholar Youmin Xi. Journal of Management Inquiry, v. 27, n. 2, p. 212-223, 2018.

Enviado em: 17/3/2020

Aprovado em: 15/7/2021

Publicado em: 10/1/2022 